\title{
Homeland, Historicity, and the Ethical of Image from the Mobilities of Image
}

Wan-I Yang

\begin{abstract}
Generally, the study of image is deeply influenced by image ontology. However, if we use image ontology as methodology, we will understand image as a copy of idea and thus be attached to truth. In doing so, we will not be able to carry out image research from the perspective of mobilities and thus ignore the significance and importance of mobilized images. Under this motivation, this paper will gradually clarify the meanings of image of mobilities, the relation between subjectivity and image, and "historical image. In the process of revealing the ethical of image, we should carry out research on affirming the mobilities of image and try to explain the influence and importance of this research on human life.
\end{abstract}

Keywords: homeland, the ethical of image, image ontology, mobilities of image

\section{Preface}

7 explore the connotation of image, many would begin with Plato's theory, and immediately perceive image as the imitation of ousia. However, if we discuss image from this perspective, it would always be confined to the concept of essence. What is more pitiful is that image would be seen as a subdivision of truth but can never be truth itself. Thus, once artists and critics set out their work, demanding and aspiring for essence and truth, then image, which was dangled in the system of truth, will be marginalized. This theory - whether consciously taken or not, will drive the artists to search for "a never returned utopia," which creates a strong sense of homeland nostalgia (die Stimmung) in the image. But what is this homeland? Where does the pity come from? Will the perplexing relation strangled between homeland and the other worlds impact the interpretation of the local land? As for the interpretation of the local "land," besides demarcating it on the world map to make it visible, we should focus more on 


\section{HOMELAND, HISTORICITY}

analyzing the "core"1 of the eyes that permeates the condition of how artists and critics see something as such.

This paper further analyzes the distinction between history and historicity from the perspective of mobilities of image. By clarifying the concept of historicity, the paper attempts to reveal the connotation of the ethical of image, ${ }^{2}$ differing from the often-discussed ontology of image.

\section{The Lost Homeland}

The world is a work of art created by the subject with its own representational ability. However, the image created by representational ability also implies the truth that cannot be revealed by representational ability. As a result, human beings are full of imagination and yearning for the untouchable idea. Therefore, in the creation of the image works, the way of negating the world highlights the truth and beauty as the lost homeland.

The way the world (le monde) appears to us as such relates to human beings' a priori capability. In other words, the spatial dimensions we perceive of the world associate with the spatial capability we have. This explains why the "world" that human beings created differs from that of other species,

${ }^{1}$ This article is concerned with the question of whether there exists a possibility that the oeuvres evolving around the themes such as homeland, locality, and nativism can be emancipated from the constraints of their attention to root, and whether the artists merely repeat the preexisting conceptual model and then merely produce the same old mode of (work) production. The further question investigates whether the signification of a work attempts to emancipate itself from the specific preexisting concept-or whether it is a kind of imitation, as Plato contends, which serves as the point of departure of this article.

${ }^{2}$ In the understanding of the "ethical of image," we can say that the way of using the word "the ethical" is more similar to the German word das Ethische, which is an adjective used in noun form. The distinction relies on the usage of "ethics," or die Ethik in German, particularly employed to highlight the differences between the ethical and "ethics" in the context of metaphysical tradition. Thus, we avoid the translation of "ethics," and use instead "the ethical."

The ethical sense used in this paper arises from Emmanuel Levinas. From Gérard Bensussan's understanding of Levinas's ethical signification, we can clearly see the differences remaining in both the ethical and the ethics. Bensussan thus writes: "The discourse ethics, the communicative ethics, the neo-Aristotelianism, the utilitarianism, the contractualism, the communitarianism, the differentialism, the meta-ethical reflection, and the applied ethics - all of the moral practical positions, sectorial or concurrent, have without doubt their effective importance of theoretical and practical point of view of the foundation and of the question of acting. All the ethics have nothing to do with the ethical on which Levinas makes the pivot point about the thinking of subjectivity" Gérard Bensussan, Ethique et Expérience: Lévinas Politique (Strasbourg: La Phocide, 2008), 8. Bensussan distinguished the difference between ethics based on moral and rational justification and Levinas's ethic beyond morality. The latter is manifested in the intrusion of the face, or more precisely, in the impact of the face on human beings. In this interpretation, we can see that ethic has a higher priority than rationality and morality, and the implication that "ethic precedes philosophy" is clarified in this priority. What Levinas puts forward, also known as "ethic of ethic" by Derrida, is "the first philosophy" whose subject is the ethical subject.

(c) 2021 Wan-I Yang

https://www.kritike.org/journal/special issue 2021/yang april2021.pdf

ISSN 1908-7330

(cc) BY-NC-ND 
despite a shared circumstance under the same sun. In the same vein, the creation of human knowledge, culture, and civilization is closely linked to human's unique capability of representation. The concept of representation can be explained from many layers, yet they all bear the same meaning of "reproduction." This definition not only reveals the relation between surface and real, phenomenon and truth, the visible and the invisible, but also shows how the subject represents the world from his/her own worldview (Weltanschauung). Such an individual worldview unveils how the (representational) world can be visibly seen, but at the same time, it beclouds the appearing (das Erscheinen/l'apparaitre ou l'apparition) of other possible world images.

Our discussion on the capability of representation could be further extended to a claim that the world (le monde) we see, in one sense, could be regarded as the artwork we created. Such art creation unveils the world in one way, yet it preinstalled a cache for the veiled, which in itself already contains an emotional space yearning for unveiling the cached. The yearning for the cached essence and truth in turn allocates value on the invisible side. Moreover, since representation already indicates an unachievable truth, creators are endowed with an ever-burning passion for the other worlds. In other cases, the feeling of an unapproachable distance will intensify along the pursuit for other worlds and creators will experience an absolute desire that always remains to be satisfied. Based on such rationale, if we try to seek truth from the images that are created by representation capability, we would experience the sense of loss that is more intense than despair (despite the absolute passion we experienced). As a result, we sometimes find that various metamorphoses of nostalgia - the yearning for Eden, the love and mourning for mother (a symbol of the homeland), the impasse of destiny, the futile consumption of passion, the decadence of this life, the ugliness of being, the worship for history-exist in the discourses of image. In different works, the meaning of homeland could be diversely approached through different forms. Yet we should note that in such works, the concept of "homeland" does not merely exist in concrete beings denoted by the creators, but also appears in the form of nostalgia for the concrete beings. Due to the dissatisfaction of being (être) and beholding (voir), one assumes that there is always a better realm of existence with higher values and happiness.

Using "homeland" to symbolize other places and "the lost homeland" to designate irretrievable beauty hidden behind the images, is actually a way to highlight an inseparable entity-the visible and the invisible-in image creations and discussions. The visible images represented are often intended to describe the invisible (or the cached) beauty. From such a point of view, the nostalgia for the homeland is not simply an actual place denoted by the artists and critics, but indeed the imagination and expectation 


\section{HOMELAND, HISTORICITY}

for the possibly better. Such general idea of a homeland (Eden/Utopia), which symbolizes the pursuit for essence and truth, is often adopted by artists and critics to endow virtual images with various contents and dreams from their own experience and imaginations. It also enables the observers to evoke their own sense of nostalgia. The images haunted by a sense of eternal loss bring its observers not only to this life or the current location, but also to the imagination of a lost happiness. Subsequently, the imagined happiness aggravates one's dissatisfaction with the reality to a deeper abyss of despair and indifference. In these situations, people may become more apathetic, or they will release the inner dissatisfaction by yelling out "This place cannot be my home." The love and hatred engendered by the comparison between the imaged homeland and reality will eventually separate homeland from reality, opposing the two sides just as truth vs. fiction, beauty vs. ugliness, and goodness vs. evil.

\section{Rule, Transgression, and the Ethical Relation}

In daily life, images as illusions are constantly refracting each other, showing the changing world as the signification of a constantly covering worldview. Just as artists put the life, which has originally no meaning, into a specific yardstick, that is, a certain sense of worldview, in order to highlight the life limited by rules as existence, and thus show the meaning of life. Different from Plato's impassable idea as the form of the phenomenal world, in the "transcendence" of norms, people highlight the significance of life and norms as a game, so as to show how the vigor and vitality of life experience and reflect on the ethical relationship between existence and norms, and thus make the meaning of norms beyond the limitations of the moral system.

When one is constrained by experience (Erlebnis), one is often engulfed into the situation. The self under such situation is a player in his/her self-represented world. ${ }^{3}$ When experience become the experienced (Erfahrung), ${ }^{4}$ the self, who has represented the world, is able to withdraw himself/herself from the world, and even separate himself/herself from the

\footnotetext{
${ }^{3}$ This seems to suggest one is in one's own dream, experiencing the world that one sees, experiencing the sadness, happiness, fear, etc.

${ }^{4}$ What is the difference between das Erlebnis and die Erfahrung? Franz Rosenzweig in his book Livret sur l'entendement sain et malsain once compared the worldview to a bowl. If "person in a flowing river" are compared to "person who experience life," then those who scoop up a ladle of water because they want to know what water is and try to understand it, just like a subject who takes a certain moment of moving life, who tries to isolate the bowl of water from the flow and explore the universal significance of water. This bowl of water, as the object of subject, is like blood flowing out of blood vessels. It is different from the life itself experienced (erleben) by human beings and has become the "Erfahrung" constructing the subject's cognition. See Franz Rosenzweig, Livret sur l'entendement sain et malsain (Paris: Cerf, 1998).
}

(c) 2021 Wan-I Yang

https://www.kritike.org/journal/special issue 2021/yang april2021.pdf

ISSN 1908-7330

(cc) BY-NC-ND 
world. At this moment, the reflective and suspicious self, is like an analyst who stands outside of the changes and mobilities of life, employing certain perspectives to reflect the world created by himself/herself and endowing his/her creation with a meaning. Reflection is a way to re-observe the memory of the self: the experienced. This is similar with analyzing our dreams. When we are dreaming, we experience the dream. But once we try to comprehend the image when we are awake, we are already outside of our creations.

To interpret the appearance is a human instinct, like the man who is discontent with only dreaming often questions about the meaning of dreams. The subject, unsatisfied with the mere experience of apparition (Erscheinung), always enquires what is the Being (être) under the appearing or apparition (Erscheinen). Just like psychoanalyst hunting for the repressed desire in one's dream, human beings, out of care, search for the multiple meanings of the world from the represented images. But the attempt to endow the world with a meaning and find an answer from the appearance, paradoxically proves that what one sees is a mere appearance ([bloße] Schein). Just as the analyst shows that dream is merely an emblem of desire, the interpretation of the image proves that appearing is merely a fabrication. But what is contained in the appearance? Is it the essence sustaining the existence of image?

In fact, not only in dreams, do we often hear people resemble life with images, such as "life is like a dream/drama." Such saying grasps the virtual and ever-changing attributions of the appearance. We, who live in the worldview of our own, display others as our own imagination. The world as such is appearing (paraitre) itself, and the interactive appearing between me and the other reflect more dimensions of the self. The multi-interwoven infinity of you and me thus dynamically reveals the universe in each instantaneous moment. Even though the universe is a fabrication, the " $\mathrm{I}$ " exists in the constant witness of such fabrication. In this sense, it is the fabrication that certifies the "I." Thus, the "I" is also an appearing image. Appearance is like the reflection from which Narcissus saw in the water.

The image of the self is, after all, a partial reflection of the " $\mathrm{I}$ " from water. If Narcissus does not insist on this single image/appearing image, then the illusion will only appear as the instantaneous false image. ${ }^{5}$ The appearing images are the evanescent illusions, and the illusions reflected with

${ }^{5}$ From Oscar Muñoz's Narcisos (1990), we can see the visage from the image gradually emerges and is formed from the water. But as the water subdues, the visage gradually disappears. The repetitive process highlights the fact that each image of appearing is similar to the self-image reflected on the pond. In the repetition between the happenings and disappearances, we can see how the self-image instantly emerges and disappears. The changes of self-image indicate the mobility of the ability to present. Only when one fixes a certain image can one fall in love with the image of self and objectify oneself into Narcissus that is fixed in a mode of being.

(C) 2021 Wan-I Yang

https://www.kritike.org/journal/special issue 2021/yang april2021.pdf

ISSN 1908-7330 


\section{HOMELAND, HISTORICITY}

each other appear as the changing universe. ${ }^{6}$ As this universe has no essence, it is distinguished from the world chained by the homogenous structure, and henceforth appears as the action of constant relocation of worldview. This constant relocation of image is the same as our ceaseless replacement of the meaning of our existence in the continuous experience of our day-to-day life, linking the illusionary universe with the structural world.

In the works of the contemporary art, we can see the artist uses himself/herself as the material of his/her work, repeating a simple rule, and tries to accentuate the relationship between life and being (such as Tehching Hsieh's work $)^{7}$ in this constant repetition. In an idiosyncratic manner, the artist repetitively brings the transforming life into the measurement of rules, sharply exhibiting the relationship between life and rule. If life is in mobility, then existence signifies the status of life structured by rule. When the artist presents (herausarbeiten) the paradox between the change of life and the rule of life to display existence, the destruction immanent to the existence of life will appear. As change relies on the essence of life, the work as such highlights the nonsense of life. However, nonsense is not no-sense; it is the attempt to emphasize how the freedom of life becoming is demolished by rules, while revealing the fact that the "life of mankind" needs such a rule to configure its relationship with other beings. ${ }^{8}$ Taking Hsieh's works - "Time Clock Piece" (1980-1981) and "Outdoor Piece" (1981-1982) - as an example, when an artist sets a particular time on the clock without falling asleep, it becomes clear that spirit is confined by body; also, it provides a dwelling space for it. When the artist sets the rule that he/she cannot enter buildings with a shelter for a year, ${ }^{9}$ the relationship between the building and the

${ }^{6}$ The image represented by me is an illusion. The world that appears as totality is only a simulacra fragmented by an All. The universe, however, appears as the virtual, bright, and fragmented worldview, and then plays in the illusion, enjoying the infinite universe reflected by the fragmentary illusions.

7 From 1970s to 1986, Hsieh completed five works of "annual action performance": “Cage" (1978-1979), “Time Clock Piece" (1980-1981), “Outdoor" (1981-1982), "Ropes" (19831984), "A Plan Not to Do Art" (1985-1986), and finally, “Thirteen Years of Plan" (1986-1999). In the last announcement, he emphatically notes that "I will make ART this time," and he will not release his further works. For further information, see Adrian Heathfield and Tehching Hsieh, Out of Now: The Lifeworks of Tehching Hsieh (Cambridge: The MIT Press, 2008).

${ }^{8}$ Freud reminds us that both life and death drive serve as the two sides of the same coin. The death and life of the cell in the everyday life, the change of life has been confined by a form (if the cell continues to disseminate itself, this will lead the humans to disease or demise). Like the appearing (paraitre) of each instance, which has been devoured in the constant becoming, the apparition (die Erscheinung) emerges in each moment but disappears in each moment too.

${ }^{9}$ In "Outdoor Piece," one is not allowed to enter in the house, but it is negated as the street fight occurs. Then the law of not entering in the house is negated as one is sent into the prison by 15 hours. These accidents seem to explain the reality of existence revealed by the negation of life of the rule as well as its opening. One has to confront the norm, and then experience the relationship between the norm and one's work (or one's existence) through

(c) 2021 Wan-I Yang

https://www.kritike.org/journal/special issue 2021/yang april2021.pdf

ISSN 1908-7330

(cc) BY-NC-ND 
humankind either as confinement or as protection is thus revealed. The nonsense of life makes life emancipated from the essence as the form that confines itself. And the self defines the rules consciously in order to reflect the relationship between one's life and one's world. From now on, the existing dimension automatically given does not only reshape the work of representation between the self and the world, but also rebuilds the ethical relationship of the world between human and the self.

Life needs some limit (i.e., forms, norms, or structure and so forth) to make existence real, providing some beautiful forms as a representational framework, like Plato who offers the Ideal as the form of phenomenal world. However, as mentioned earlier, the transcendental limit indeed evokes the sense of nostalgia. Then the question appears as such: Can existence itself provide another measurement of life, rather than the transcendental ideal form, that makes the representational world appear as my existence? The search for the logos of the representation existence then becomes the pivotal point of appearing the image of existence. But what measurement is needed to gauge our existence and make it visible? If image is no longer the surface that contains the essence, then the inquiry about image firstly concerns about setting measurement for the existence. The measurement coming from existence does not signify a truth that one cannot transgress. On contrary, it is the transgression beyond the norm that underscores the existence. The transgression beyond the norm does not only exhibit the existence and norm, but also displays the intensity and vitality of life. Thus, in contrast to the traditional unchallengeable truth, the measurement in existence is, for Georges Bataille, meant to be crossed or transgressed..$^{10}$ The conflicts arising from the constant experiences of transgression further invite us to consider what measurement and what manner can be made to represent the relationship between the artist and the world. What this inquiry concerns serves as an attempt to reshape the representation of the one's existence and the ethical relationship between the human and the world. The ethical relationship here highlights the experience or the lived-experience in transgression as well as the reflection of the action between existence and norm, which stands in contrast to the constraining simple meaning. Hence, the ethical relationship exhibits the rethinking and the reshaping of meaning

transgressing the norm. The opening compels the artists not to act in accordance with the norm, but constantly return themselves to the relationship between existence and norm, or the conflicts between life and existence experienced, again and again, by the accidents.

${ }^{10}$ For Bataille's idea of "Transgression," see Georges Bataille, Oeuvres Complètes X (Paris: Gallimard, 1987), 66.

(C) 2021 Wan-I Yang

https://www.kritike.org/journal/special issue 2021/yang april2021.pdf

ISSN 1908-7330

(cc) BY-NC-ND 
in the act of transgressing the norm, remaining in contrast to the questions involved in the autonomy and heteronomy of the closed morality. ${ }^{11}$

\section{The Other Meaning of Homeland from the Self as a Fissure (Riss)}

The position of "self," the empty subject, makes the virtual self-image flow and thus avoids the formation of identical self. This fissure, which avoids the materialization of life into a being, is the manifestation of existence, but it is not life itself. If this subjective position is regarded as homeland, thus the meaning of homeland will be shown as "circulation." The images that "circulate" in this fissure do not rely on the essence to prove themselves. Therefore, it is no longer necessary to talk about the meaning of image from the image ontology which triggers the thoughts and feelings. On the premise that mobility is the relationship between image and image, the ethical of image should be carried out.

Reshaping the self-image concerns the deconstruction and construction of appearance of the self. The self-image, during its mobilities, appears as the trace of multilayered interlacing appearances.

Between the deconstruction and construction of self-image, the pure form of "self-nature," appearing as the measurement of the self, becomes the core of existential meaning and the eye of structure. The empty hole of "selfnature" grants not only life's nihility and limit, but also the cause that makes us human. The homeland without content, due to its empty void nihilism, becomes the standard of raison d'être and marks the relationship of ego and the alter ego (the subject and the other). The black hole of the center is the core and the weakness of the structure. The self thus appears as the fissure of structure. Just as norm presupposes transgression, the hero always becomes himself/herself because of his/her weakness and dies on the same cause. The prominence of the phallus inevitably presupposes castration, as well as the relationship between father and the family name presupposes patricide and betrayal. The core of existence is also the fissure (Riss) of structure. It gathers together the meaning of life, but it also devours the meanings like the nihilistic root. ${ }^{12}$

The position of the subject that assembles the changes of life into existence becomes the "position" of all phenomena for its emptiness. Francis

${ }^{11}$ From the mobile relationship of the ethical of image, we are reminded of Nicolas Bourriaud's Relational Aesthetics, in which Bourriaud offers the definition of the relational (art). The relational (art) relation does not indicate independent and private space, but the aesthetic creation departing from the theory and practice between the human relations and the social context. See Nicolas Bourriaud, Relational Aesthetics (Dijon: Éditions Presses Du Reéel, 1998).

${ }^{12}$ If we identify the void of care to redemption (that is, the desire to fill in the void of self, which awaits the coming of messiah), this doing cannot still escape the nostalgia mentioned above.

(c) 2021 Wan-I Yang

https://www.kritike.org/journal/special issue 2021/yang april2021.pdf

ISSN 1908-7330

(c) $\mathrm{BY}-\mathrm{NC}-\mathrm{ND}$ 
Bacon's Study for the Head of a Screaming Pope (1952) serves as an example. The open mouth surrounded by the painting is the fissure towards the inside and outside. The open mouth grants space the ability to change, twist and flow. This hole serves as the center that assembles the representation, as well as the runaway path of the representation. As the measurement of the painting, the two conflicting forces converged in this core, and formed the tensions that saturated the whole painting, casting a dynamic illusion to the static painting. We can name this as the position of the subject, the punctum, the fissure, the crevasse, and so on. Similar to Oscar Muñoz's Le début et la fin de Narcisse (2002), there are two displaced face images on the pond. As the two images converge together, the water reflected on the image immediately flow away from the leakage. In this work, firstly, the reflection on water still presents two moving false images, just like Narcissus who, in the beginning, knows that the face reflected on the pond is just his reflection and understands that the reflection changed in the flow is a mere false image. Then Narcissus gradually identifies this false image as true when the reflection continues to exist on the tranquil water. Muñoz slowly overlaps the two images to reveal Narcissus's gradual identification with the false image as time goes by. What he attempts to accentuate is the identification process of the false image in time. When the doubled images symbolizing the fulfillment of identification overlapped on the water, the water leaks the light and erupts through the hole in a spiral manner. Meanwhile, the destruction and fissure of the image come to the fore. When Narcissus recognizes the image and is objectified as daffodil, the crack of the subject instantly appears in the death of the moving image. Muñoz's work reveals that once the mobilities of image are captured by identity, its movability and changeability will ephemerally disappear, and the self will appear in the emptiness as well. Once the dynamic appearance is objectified, ${ }^{13}$ the self that traverses the representation will be brought into the nihilism (like the obvious and useless leaking hole, which appears as the crack of the pipe). The nihilism of the self exists for the traversing, which, in such a manner, ensures the dynamism and the possibility of life. This appears like a key knot that welcomes the future, while Being can move as a crack and life can have a hole for breathing.

Self, the virtual position, twisting point, passage, homeland, fissure, and crack, is an open and empty form: ${ }^{14}$ nihilism. For existence that appears depending on nihilism, homeland is the exit of life, but not the life itself; it is the existence that appears, but not existence itself. The emptiness waiting to

\footnotetext{
${ }^{13}$ Narcissus sees his own reflection on the water, falls in love with the reflection, and then becomes objectified-or dies-as the flower Narcissus. This example indicates that the identity affirmed by the mirror image or the appearing image serves as the key to existence of immobility.

14 The self-image begins with this opening, and disappears, too, with this.
} 
be filled in is, however, a passage that one can never fill up. It is not an object, but a passage; it does not become existence, but makes representation possible. The core of the passage-like the projector that renders image possible to appear and the eyes that renders vision possible-does not become static in itself but consumes itself to make the image appear. Such saying underscores the ambiguity of homeland, making homeland itself different from the most primary and essential raison d'être, and thus becomes the virtual emptiness that makes various possibilities able to appear. Hence, homeland appears as a bridge for access and cultivation. The mobilities of life make it different from the enclosed, grasped, and maintained fixed closed area. The bridge of understanding, which appears on its access to opinions from all directions, exists on its open possibilities for all directions. We can name the relational care configured by the representations flowing in the core the "ethic of image." From this rationale, we could know that image does not necessarily need to prove itself from the perspective of essence. Image can actualize the relationship between images through its intrinsic changes and emancipate the world from the existed structure. Meanwhile, this will create more dynamic modes of existence. Thus, when we observe various works of image, the colorful universe presented by the interplay of images is not merely Plato's contention of a copy on phenomenon. When phenomenon passes through the passage of the artist and reconstructs the relationship of image in the representation of the appearances, the work obviously has shown the artist's care. The ethic of the image hereby appears in the work, and, through this, reveals more possibility of life.

\section{History of the Image or the Image of Historicity}

If we call collecting, classifying, summarizing, and studying the image development of creators' worldviews in different times as "the history of images," then the research on the history of images that has already taken place does not seem to be able to highlight the characteristics of mobilities of images. Therefore, in the promotion of "the ethical of image," "image of historicity" is put forward, which emphasizes the mobility and variability of images. In the process of dynamically remolding subjectivity, it challenges the existing concepts, taboos, or history simultaneously, making the image become the driving force to promote the progress of people and the world.

Since the pursuit of "lost homeland" implied in the image ontology will lead to the pursuit of Eden in the creation of image, the mobilities of image $^{15}$ are affirmed by "the ethical of image." In the affirmation of the

${ }^{15}$ Different from the image ontology that image is attached to the essence, the mobility of image means that the image circulates, in an eternal returning way, between the images of subjectivity, giving the possibility of reconstructing the meaning of human and the world.

(C) 2021 Wan-I Yang

https://www.kritike.org/journal/special issue 2021/yang april2021.pdf

ISSN 1908-7330

(c) $\mathrm{BY}-\mathrm{NC}-\mathrm{ND}$ 
mobilities of images, images have the historicity of a synchronous development with the creators' life. What is the difference between "historical image" and "image of historicity"? The following passage will try to explain. The humans, armed with the capability of representation, accomplished massive image works through the immanent drive of making imagination visible.

Facing the gigantic image industry, analysts extensively read image works, and induce the development of image from them. Through the categorization of the image works, analysts also categorize the styles of the artists and then encode ${ }^{16}$ the reproduced images to conduct the research on the history of images. These research highlight artists' worldview (Weltanschauung), and also sum up the themes with constant attention. But for the mobile and virtual image, which does not aim at serving for essence, the past inquiry of image history does not suffice to reveal its characteristics. If we merely approach the "form" of image characteristics as the research rule of image, do we take the risk of categorizing the image within a certain concept, constraining image in a certain worldview that conceptually subjects the image as the historical evidence and that, then, ignores the mobile, dynamic, and open possibilities of image?

The mobilities of eternal return of an image departing from the nihilism underscore the virtuality and the mobilities of image. Different artists with various worldviews provide more possible ways to represent the colorful universe. The image that disappears in each instant configures a virtual world different from reality. Just as Nicolas Bourriaud contends in Relational Aesthetics:

Artistic figure contemporary with the invention of film. The artist takes his camera-subjectivity into the real, defining himself as a cameraman: the museum plays the part of the film, he records. For the first time, with Duchamp, art no longer consists in translating the real with the help of signs, but in presenting this same real as it is (Duchamp, the Lumière brothers...) $)^{17}$

The appearance self-framed by the emptiness is a certain virtual world constructed by the fragmentary images extracted from the subject's dynamic shots on reality. This world produced through subjectivity includes

\footnotetext{
16 The encoding uses several kinds. The most common one is the encoding by time (period) or space (location).

${ }^{17}$ Bourriaud, Relational Aesthetics, 57.
} 
reality into itself through image, and the image swallowed by the self immediately starts to ruminate the image, which, in the reconstruction of the image, endows the image with different meanings, which initiates the relationship between the self and image.

The process of the image creation henceforth appears as the mobile self, experiencing the relationship between self and reality. This activity does not only make the artist part of the image, but also endows the image the historicity that simultaneously born with the artist's life. The image of historicity does not only revitalize the subject in process, but also dynamically reshapes the subjectivity, challenging the existing notion, taboo, or history in its manner of dynamism and mobilities. Thus, the relationship concerning the ethical of image not only emancipates the artists from the confinement of reality, but also provides experiences on the fluidity of life out of the existence of the self. Moreover, it allows work with a personal touch to differentiate itself (i.e., the dynamic historicity) from the recording-oriented historical image. The image relationship extended from the artist will not only allow the spectators to have historical knowledge and developmental history of image, but also even merge into the world of the artist and experience the dynamic world.

\section{Conclusion}

Image is not simply the copy. Once image passes through the passage of subjectivity, it is not the primary reality anymore. Subjectivity as the homeland of image is not the lost elsewhere, but "here" that image constantly passes but never stays. The meaning of homeland or locality thus appears as the bearer of the genesis or mobilities. If image is the endless flowing water, then the subjectivity will be the river (the projector or the video camera). The water on the river instantly creates the powerful surges, just like the instantaneous images, or the world constituted by the traces of the retina or the film of the movie. The world is like the movie. Prior to Heraclitus's motto "no man ever steps in the same river twice," the mode of being exhibited by the temporality of the movie unfurls the irretrievable event or humankind's finite time. Image constantly transgresses the limit of time to make multiple worlds appear through its innovation, and it allows the humankind to experience more possibilities in the finite life. The instant image emancipated from the confinement of the existing structure between humankind and the world, the relationship between one and the self, the others and the world, has been, again, reformed and reshaped. The visibility appeared as the multiplicity and the possibility of being not only can make the invisible and the visible coexist in image, but can also reinforce humankind's capability of

(c) 2021 Wan-I Yang

https://www.kritike.org/journal/special issue 2021/yang april2021.pdf

ISSN 1908-7330

(cc) BY-NC-ND 
representation to go beyond reality, even manifesting imagination in reality through image.

The image between the existence of representation and the ethical relationship bears the possibility of reshaping the relationship between the other and the world. Image may not be aimed for reshaping, but since it is the production of human representation, it attempts to render the immanence of the invisible visible. The image that embodies the visible and invisible, debunks the binary opposition between representation and reality, allowing human beings to exist in the world constituted by reality and imagination. From the development of the Internet virtual world, we can see that today's world is heading towards this direction. Like today's society, many young people, born in this Internet world, are accustomed to dealing with the people in the virtual world more often than those in the actual world. Born and raised in such an environment, they feel more affectively and intimately close with the virtual world, rather than the life world. In this sense, the virtual image has become the focus of their life. So how should we adjust the relationship between the virtual image and the real life? Does the principle of dealing with the real-world people still apply to that with the virtual world? I contend that these are ethical questions that we need urgently to raise.

Image brings human beings a certain dimension of freedom. In the emancipated existence, human beings are able to see many possibilities. How should human beings face themselves, the others, and the world in such a world? This is an urgent question for us to ponder, external to experiencing the ethical relationship reshaped by image. Once the ethical relationship of mobilities becomes an experience, we will find that the change of existential mode of human beings living in the image world between reality and imagination has great impact on the self and existence. Living in the image world, we experience its mobilities. The image ontology, which holds that images are always attached to truth, affirms the truth and denies the value of the study on the mobilities of images. On the contrary, "the ethical of image" affirms the mobilities of images, which constantly liberates people and the world from the established structure, making the relationship between themselves, others, and the world reshaped again and again. Therefore, when researchers take the ever-changing ethical relationship as an empirical reflection, they will find that this dynamic nature challenges the existing concepts, taboos, or history, and has already made the image become the driving force for the advancement of human beings and the world. If we try to interpret the study of image as the reflection of experience, then should we go beyond the givens of experience and embark on the inquiry to the future exhibited by the mobilities of being in the image? If the creation of image endows possibility of new meanings, should we, in the notion of image, offer meaning or warning to the future from the perspective of historicity? These 


\section{HOMELAND, HISTORICITY}

are the focuses and inquiries that we, situated in the flow of images, will continue to make.

Institute of Philosophy, National Sun Yat-sen University, Taiwan

\section{References}

Bataille, Georges, Oeuvres Complètes X (Paris: Gallimard, 1987).

Bensussan, Gérard, Ethique et Expérience: Lévinas Politique (Strasbourg: La Phocide, 2008).

Bourriaud, Nicolas, Relational Aesthetics (Dijon: Éditions Presses Du Reéel, 1998).

Heathfield, Adrian and Tehching Hsieh, Out of Now: The Lifeworks of Tehching Hsieh (Cambridge: The MIT Press, 2008).

Rosenzweig, Franz, Livret sur l'entendement sain et malsain (Paris: Cerf, 1998). 